\title{
Selection of Superior Clones by Stability Analysis of Growth Performance in Populus davidiana Dode at Age 12
}

\author{
By Y. B. Koo, J. K. Yeo, K. S. Woo*) and T. S. Kim
}

Department of Forest Genetic Resources, Korea Forest Research Institute 44-3, Omokchun-dong, Suwon, Kyunggi-do, 441-350, Korea

(Received $13^{\text {th }}$ September 2005)

\begin{abstract}
Stability parameters and clone $\mathrm{x}$ site interactions for 12-year volume were investigated in seven Populus davidiana (Korean aspen) clonal trials in South Korea. Either 24 or 38 clones were tested in each of the seven sites. All sources of variables such as clone, site, and clone $\mathrm{x}$ site interaction were statistically significant $(p<0.01)$ in the analysis of variance. The average volume of 3,199 trees was $0.043 \mathrm{~m}^{3}$. The different types of stability were shown from selected clones against the test means for volume. Clone Palkong 2 represents a relatively unstable clone that is sensitive to site changes and had greater adaptability to favorable sites.

Five clones, Odae 19, Taehyun 9, Sunyeo 4, Sokwang 31 , and Taehyun 3, were selected as superior clones based on stability parameters and mean volume. The selected clones have average stability and performed in a predictable manner over different planting sites. A positive relationship between stability parameters and the clone mean performance for volume was noted in this study.
\end{abstract}

Key words: Stability parameters, clone x site interactions, Populus davidiana, adaptability, superior clones.

\section{Introduction}

Populus davidiana belongs to Treppidae, a sub-section of section Leuce. It grows relatively fast and frequently occurs over $500 \mathrm{~m}$ in elevation in Korea ( $\mathrm{NoH}$ et al., 1997). Poplar breeding programs for commercial purpose began in northern Europe in the 1940s with a cross between $P$. tremula and $P$. tremuloides (HYNYEN and KARLSSON, 2001). In Korea, poplar plantation used to be an important component of rural landscape. It not only played a role as a ground cover but also provided an income source to local farmers. Before 1980s, $P$. euramericana was the dominant species in the majority of poplar plantations that were typically established along the riverbank. The total plantation area reached about 580,000 ha by the end of 1980 (Korea Forest Service, 1992). However, during the early 1980s, "the River Act" legislated in Korea strictly prohibited poplar planting along the riverbank because they might cause flooding during rainy season. Therefore, the species lost its right planting sites and showed poor performance when planted on hillside. As a result, an aspen breeding program began in the late 1980's with the selection of fast growing and drought tolerant trees from natural populations in Korea to move poplar plantations to upland

\footnotetext{
*) Communicating author: KwAN-Soo Woo, Telephone: 82-31-290 1106, Fax: 82-31-292-4458. E-mail: woo9431@foa.go.kr.
}

area. The aim of the program was to develop varieties that could replace $\mathrm{x} P$. euramericana, which usually does not grow well in upland area. $P$. davidiana is mainly distributed in northeastern Asia including Korea. In addition to having a good biomass, it grows well even at high elevation where other poplar species could not survive. However, growth performance of $P$. davidiana clones varied severely among different environments ( $\mathrm{NoH}$ et al., 1997). Therefore, it was important to select the right aspen clones and utilize them in the right sites.

Genotype-environment $(\mathrm{GxE})$ interaction is defined as the differential response of genotypes to environmental changes (ISIK and KLEINSCHMIT, 2003). Understanding $\mathrm{GxE}$ interaction is important in selecting hybrids better adapted to diverse environments as well as in determining test environments in breeding programs (JONG and BREWBAKER, 2005). Many researchers have shown GxE interaction in growth of clones and varieties (CLAIR and Kleinschmit, 1986; PAUL et al., 1997; YU and PUlkKinen, 2003). For example, significant clone $\mathrm{x}$ site interaction was found for the 40 clones of the Norway spruce tested on seven contrasting sites in northern Germany (Clair and Kleinschmit, 1986). Clones give a more sensitive means of determining $\mathrm{GxE}$ interactions than either seed sources or families because non-additive gene effects might contribute (BENTZER et al., 1988). YU and PULKKINEN (2003) evaluated GxE interaction and stability in growth of hybrid aspen clones (P. tremu$l a \times P$. tremuloides) using a dynamic concept of stability, clonal repeatabilities, and genetic gain. They found significant site $\mathrm{x}$ clone interactions in height and basal diameter in 3- and 4-year-old trees and expected $17 \%$ of genetic gains for height growth increment during the third year from selecting fast growing clones.

Stability or constancy of a genotype (individuals, clones, or populations) is the characteristic that is not affected by environmental changes. The advantage of superior genotype selection through stability analysis over average performances is that stable genotypes perform dependably across environments, reducing $\mathrm{GxE}$ interaction. The selected genotypes will increase genetic gains by allowing breeders to optimally deploy them to various sites. However, most stability works with trees have been conducted with only a few genotypes, seed sources or clones, and those have been tested across a limited range of environments (YEISER et al., 1981; BARNES et al., 1984; Yu and PULKKINEN, 2003).

In randomly selected natural aspen stands, annual increment of growth was investigated to estimate both the rotation age and the optimum age for early selec- 
tion. While the optimal rotation age was found to be 32 years, early selection could be made as early as six years after planting ( $\mathrm{NoH}$ et al., 1990). NoH et al. (1997) selected $P$. davidiana clones at ages six and seven when they were not only superior in growth performance but also stable over a range of environments. They used stability parameters such as mean square deviations and regression coefficient shown by EBERHART and RUSSELL (1966). They selected 7 clones out of 58 from seven sites: one clone that performed well in good sites, and three clones that adapted relatively well to poor sites, and another seven that did fairly well in all sites. However, since the planting was done separately in both 1991 and 1992, the difference in height growth was estimated with a few overlapping clones (reference clones) planted across all sites.

In this study, we investigated 12-year volume growth of the clones in both 1991 and 1992 plantings to clarify the effect of genotype-environment interaction in 12year volume growth of 57 clones of $P$. davidiana; to estimate rank-based stability-related clonal parameters; and to select superior clones based on the combination of stability, growth performance and adaptability over 7 trials.

\section{Materials and Methods}

\section{Plant material}

In total, 258 trees were selected in the natural stands based on their growth performance throughout the nation (NoH et al., 1997). Root cuttings were taken from the selected trees and planted horizontally at a depth of $3-4 \mathrm{~cm}$ in the greenhouse. Suckers were propagated vegetatively by the method of $\mathrm{NoH}$ et al. (1988) in a nursery. Based on nursery performance, 24 of 52 clones and 34 of 100 clones were selected in 1990 and 1991, respectively (NoH et al., 1992). The selected 24 clones and a control clone (Clivus: $P$. alba $\times$ P. glandulosa) were planted in 1991 at each of four sites (Table 1) including Banwol in Kyeonggi province (KB), Cheongju in Chungbuk province (CC), Yimsil in Jeonbuk province (JY), and Geochang in Kyongnam province (KG). Among the 34 clones selected in 1991 ( $\mathrm{NoH}$ et al., 1992), one clone, "China 6," was excluded in this study.

In 1992 planting, a total of 39 clones, including 33 selected clones, a control clone, "Clivus", and five over- lapping clones (Paekdam 15, Ponghyun 4, Pukdae 12, Sukam 2, and Hama 1) planted in 1991, were included at each of three sites (Table 1) such as Youseong in Daejeon (DY), Hwasoon in Jeonnam province (JH), Youngju in Kyongbuk province (KY). The "Clivus" was included in both years to compare its growth performance with other aspen clones since it is one of the best hybrid clones developed in Korea. However, Clivus was not included in stability analyses. The experimental design of the seven trials was a randomized complete block design with 10 rooted cuttings per replication in each of three replications. Planting space was $3 \mathrm{~m} \times 3 \mathrm{~m}$ at all sites.

\section{Data analysis}

Since the seven trials were planted in two different years, the final growth performance was measured at age 12 (2002 and 2003, respectively). The data from these 57 clones' ( 24 in 1991 and 33 in 1992) were used to rank the clones for volume growth. Volume $\left(\mathrm{m}^{3}\right)$ was calculated using the equation below:

$$
\begin{aligned}
\mathrm{V}=\mathrm{H} \times \mathrm{D}^{2} \times 0.3533 \\
\text { where } \mathrm{V}=\operatorname{volume}\left(\mathrm{m}^{3}\right) \\
\mathrm{H}=\text { height }(\mathrm{m}) \\
\mathrm{D}=\operatorname{diameter}(\mathrm{m})
\end{aligned}
$$

The following analytical model was used to determine the effects of genetic and environmental factors on the growth performance of the clones:

$$
\mathrm{Y}_{\mathrm{ijk}}=\mu+\mathrm{C}_{\mathrm{i}}+\mathrm{S}_{\mathrm{j}}+\mathrm{B}_{\mathrm{k}(\mathrm{j})}+(\mathrm{CS})_{\mathrm{ij}}+\varepsilon_{\mathrm{ijk}}
$$

where $\mathrm{Y}_{\mathrm{ijk}}$ : growth performance of the ith clone in the kth block and jth site

$\mu$ : overall mean

$\mathrm{C}_{\mathrm{i}}$ : effect of ith clone $(\mathrm{i}=1,2,3, \ldots, \mathrm{v})$

$\mathrm{S}_{\mathrm{j}}$ : effect of $\mathrm{jth}$ site $(\mathrm{j}=1,2,3, \ldots, \mathrm{p})$

$\mathrm{B}_{\mathrm{k}(\mathrm{j})}$ : effect of kth block nested in the jth site

$(\mathrm{CS})_{\mathrm{ij}}$ : interaction of the ith clone and jth site

$\varepsilon_{\mathrm{ijk}}$ : error effect

The sites were treated as fixed effects whereas the clones were treated as random effects.

\section{Stability parameters}

The following joint regression model was used to estimate clonal performance upon environmental index

Table 1. - Description of test sites.

\begin{tabular}{ccccccc}
\hline Site $^{\mathrm{A}}$ & Latitude & Longitude & Elevation $(\mathrm{m})$ & Slope $(\%)$ & Aspect & Soil \\
\hline $\mathrm{KB}$ & $37^{\circ} 14^{\prime}$ & $127^{\circ} 05^{\prime}$ & 150 & $10 \sim 15$ & Southwest & Sandy loam \\
$\mathrm{CC}$ & $36^{\circ} 37^{\prime}$ & $127^{\circ} 33^{\prime}$ & 220 & 30 & Northeast & Clay loam \\
$\mathrm{JY}$ & $35^{\circ} 38^{\prime}$ & $127^{\circ} 15^{\prime}$ & 300 & 20 & Northeast & Sandy loam \\
$\mathrm{KG}$ & $35^{\circ} 45^{\prime}$ & $127^{\circ} 42^{\prime}$ & 600 & $15 \sim 20$ & Northeast & Sandy loam \\
$\mathrm{DY}$ & $36^{\circ} 23^{\prime}$ & $127^{\circ} 18^{\prime}$ & 140 & 5 & North & Sandy loam \\
$\mathrm{JH}$ & $35^{\circ} 02^{\prime}$ & $127^{\circ} 01^{\prime}$ & 260 & 10 & Southwest & Sandy loam \\
$\mathrm{KY}$ & $36^{\circ} 49^{\prime}$ & $128^{\circ} 31^{\prime}$ & 650 & $15 \sim 20$ & Northwest & Clay loam \\
\hline
\end{tabular}

A KB: Kyeonggi-Banwol, CC: Chungbuk-Chungju, JY: Jeonbuk-Yimsil, KG: Kyongnam-Geochang, DY: Daejeon-Youseong, JH: Jeonnam-Hwasoon, KY: Kyongbuk-Youngju. 
(FInLAY and Wilkinson, 1963; EBERHART and Russell, 1966; PERKINS and JINKS, 1968):

$$
\mathrm{Y}_{\mathrm{ij}}=\mu_{\mathrm{i}}+\beta_{\mathrm{i}} \mathrm{I}_{\mathrm{j}}+\delta_{\mathrm{ij}}
$$

where $Y_{\mathrm{ij}}$ : growth performance of the ith clone at the jth site $(i=1,2, . ., v ; j=1,2, . ., p)$

$\mu_{\mathrm{i}}$ : mean growth performance of the ith clone

$\beta_{\mathrm{i}}$ : regression coefficient of the ith clone

$I_{j}$ : environmental index of the jth site

$$
\left(I_{j}=\frac{\sum_{i=1}^{v} Y_{i j}}{v}-\frac{\sum_{i=1}^{v} \sum_{j=1}^{p} Y_{i j}}{v p}\right)
$$

$\delta_{\mathrm{ij}}$ : error effect

$$
s_{i}^{2}=\frac{\sum_{j=1}^{p} \delta_{i j}^{2}}{(n-2)}: \text { mean square deviations }
$$

The estimated regression coefficient $\beta_{i}$ of clonal performance was used for measuring stability and relative adaptability (FINLAY and WILKINSON, 1963). A clone with $\beta_{\mathrm{i}}$ value close to one was considered to have average stability and thus well adapted to both good and poor sites. A clone with $\beta_{i}$ value greater than one was of low stability and better adapted to good sites. Since either 24 or 38 clones were tested in each of the seven sites, an environment index (I) was obtained only from 24 clones selected in each region to minimize any bias from unbalanced data. EBERHART and RUSSELL (1966) already proposed an additional stability parameter, the mean square deviations (s2i) from the regression for each genotype. According to the regression model, a stable clone is defined as one with $\mathrm{s}^{2}{ }_{\mathrm{i}}=0$ and $\beta_{\mathrm{i}}=1$.

Even though the clones were planted in different years, we tested and statistically compared both groups together for stability. Using the GLM procedure, the data from 790 individuals (clone Clivus not included) planted in both planting years were analyzed. The results showed no statistical difference $(P=0.234)$ for volume between the two different planting years. Instead, differences were significant in volume among sites and clones (data not shown). To determine differences in volume among sites and among clones, we performed analysis of variance using the SAS-PROC GLM statistical package and type III sums of squares (SAS INSTITUTE INC., 1989).

\section{Results and Discussion}

\section{General growth performance of clones}

Performance levels for 12-year height and DBH were used to rank clones for mean performance over all seven-test sites. Average height and $\mathrm{DBH}$ of 57 clones $(3,199$ trees $)$ planted in the seven sites at age 12 were $9.3 \mathrm{~m}( \pm 2.93)$ and $10.0 \mathrm{~cm}( \pm 3.72)$, respectively. The mean volume at age 12 over the seven sites was $0.043 \mathrm{~m}^{3}( \pm 0.042)$, and varied among sites (Tables 2,3 ). The clone Palkong 2 ranked first in mean volume $\left(0.099 \mathrm{~m}^{3}\right)$. The best individual tree in volume growth at age 12 also belonged to the clone Palkong 2 that planted in the site $\mathrm{JH}$, showing $17.9 \mathrm{~m}$ of height, $27.6 \mathrm{~cm}$ of $\mathrm{DBH}$, and $0.482 \mathrm{~m}^{3}$ of volume.

In our earlier study with the same test plants, survival rate at age six was $61 \%$ and $65 \%$ in 1991 and 1992 plantations, respectively ( $\mathrm{NoH}$ et al., 1997). At age 12, however, it was reduced to $47 \%$ and $53 \%$, respectively. The survival rates varied among the sites. One of the two sites showing the lowest survival rate $(39 \%)$ at age 12 was the site DY that had been a poplar plantation before planting our clones. $\mathrm{NoH}$ et al. (1997) suggested that survival rate of aspen appeared to be significantly reduced when a site was continuously reused for the cultivation of the same species. In the case, soil usually suffers from multiple nutrient deficiencies and nutrient balances are significantly impaired. In addition to nutrient deficiency, canopy overlapping by dense planting space $(3 \mathrm{~m} \times 3 \mathrm{~m})$ might have caused the mortality of some clones in the later stage. Relatively low survival rate $(39 \%)$ at the site $J Y$ is attributed to the damaging effects of a typhoon, which passed the site.

Ryan-Einot-Gabriel-Welsch multiple range tests at $5 \%$ level for volume across the seven sites is presented in Table 4. The sites could be divided into five groups according to their volume growth. The site CC ranked first in mean volume and it was followed by the site groups JH, JY-DY-KY, DY-KY-KG, and KB (Table 4). Since there was no statistical difference for volume growth between the two planting years as mentioned earlier, variation for volume among sites appeared to respond to interactions among altitude, slope and nutrient availability. The site CC supported the best volume growth probably because it has a proper slope (30\%), good drainage, and clay soil with excellent water- and nutrient-holding capacity. Whereas three sites (CC, JH, JY) located at intermediate elevation between 200 and $300 \mathrm{~m}$ produced high mean volume, two sites (KY and $\mathrm{KG}$ ) at higher elevation (over $600 \mathrm{~m}$ ) yielded relatively lower volumes among all test sites although the difference was not significant (Table 1).

Analyses of variance for volume at age 12 at each of the 7 sites are presented in Table 5 . All sources, including clone $\mathrm{x}$ block interaction, were statistically significant $(\mathrm{P}<0.05)$ in the overall analysis of variance, except the clonal effect in JY and block effect in DY. Volume growth differed significantly at each site. At the site KB, the clone Pukdae 11 produced volume growth of $0.035 \mathrm{~m}^{3}$, which is nearly ten times as much volume as the clone Taehyun 1 (Table 2). However, the clone Taehyun 1 performed best in the site JY producing $0.084 \mathrm{~m}^{3}$. The clone Palkong 2 in the site $\mathrm{JH}$ showed the highest volume growth of $0.208 \mathrm{~m}^{3}$, which is twenty-six times as much as the clone Sukam 5 (Table 3). A clone showing the best performance in one site was a poor performer in another site, indicating that mean 12-year volumes of $P$. davidiana clones varied depending on where they were grown.

\section{Stability analysis}

Values for the regression coefficient $\left(\beta_{\mathrm{i}}\right)$ ranged from -0.05 to 7.95 , and the different types of stabilities were shown from selected clones against the test means for volume (Table 6). The clone Kooma 2 represents a clone 
Table 2. - Survival rate and mean 12-year volumes of 25 P. davidiana clones planted in 1991.

\begin{tabular}{|c|c|c|c|c|c|c|c|c|c|c|c|}
\hline \multirow{2}{*}{$\begin{array}{c}\text { Planting } \\
\text { year }\end{array}$} & \multirow{2}{*}{ Clone } & \multicolumn{5}{|c|}{ Survival rate(\%) } & \multicolumn{5}{|c|}{ Volume $\left(\mathrm{m}^{3}\right)$} \\
\hline & & Mean* & $\mathrm{KB}^{\mathrm{A}}$ & $\mathrm{CC}$ & JY & $\mathrm{KG}$ & Mean & KB & $\mathrm{CC}$ & JY & KG \\
\hline & Kooma 1 & 49 & 30 & 77 & 40 & 50 & 0.06589 & 0.00912 & 0.08405 & 0.02889 & 0.01742 \\
\hline & Kooma 2 & 41 & 63 & 47 & 27 & 27 & 0.01610 & 0.00392 & 0.07497 & 0.02862 & 0.00465 \\
\hline & Taehyun 1 & 41 & 27 & 60 & 33 & 43 & 0.03071 & 0.00354 & 0.05096 & 0.08423 & 0.01649 \\
\hline & Taehyun 3 & 58 & 47 & 63 & 50 & 70 & 0.03283 & 0.01577 & 0.09106 & 0.03837 & 0.03851 \\
\hline & Paekdam 15 & 63 & 60 & 57 & 53 & 83 & 0.06096 & 0.01355 & 0.11069 & 0.04961 & 0.04933 \\
\hline & Paekdam 5 & 43 & 33 & 43 & 43 & 53 & 0.04914 & 0.01844 & 0.11569 & 0.04202 & 0.02862 \\
\hline & Ponghyun1 & 41 & 40 & 57 & 37 & 30 & 0.04735 & 0.00625 & 0.05143 & 0.03123 & 0.01851 \\
\hline & Ponghyun4 & 46 & 37 & 63 & 40 & 43 & 0.05653 & 0.00996 & 0.07091 & 0.04720 & 0.03396 \\
\hline & Pukdae 11 & 63 & 63 & 80 & 50 & 57 & 0.05940 & 0.03506 & 0.05499 & 0.03000 & 0.01755 \\
\hline & Pukdae 12 & 43 & 40 & 47 & 37 & 50 & 0.01613 & 0.00702 & 0.06140 & 0.02083 & 0.02182 \\
\hline & Pukdae 3 & 51 & 60 & 53 & 43 & 47 & 0.02245 & 0.00851 & 0.03417 & 0.02103 & 0.00482 \\
\hline & Pukdae 6 & 65 & 57 & 63 & 50 & 90 & 0.04896 & 0.01599 & 0.07833 & 0.03542 & 0.04493 \\
\hline \multirow[t]{14}{*}{1991} & Pukdae 7 & 42 & 27 & 47 & 43 & 50 & 0.04541 & 0.01821 & 0.08019 & 0.02820 & 0.05539 \\
\hline & Pukdae 9 & 38 & 43 & 50 & 27 & 30 & 0.01659 & 0.00691 & 0.03727 & 0.03138 & 0.00996 \\
\hline & Sangma 1 & 40 & 53 & 50 & 27 & 30 & 0.02927 & 0.00883 & 0.03523 & 0.00938 & 0.00649 \\
\hline & Sunyeo 3 & 43 & 50 & 43 & 47 & 33 & 0.02896 & 0.00547 & 0.13451 & 0.02681 & 0.04387 \\
\hline & Sunyeo 4 & 53 & 43 & 83 & 37 & 50 & 0.04419 & 0.00681 & 0.09800 & 0.04692 & 0.03482 \\
\hline & Sunyeo 6 & 44 & 13 & 73 & 37 & 53 & 0.02913 & 0.00359 & 0.07284 & 0.02875 & 0.03538 \\
\hline & Sukam 1 & 50 & 63 & 60 & 33 & 43 & 0.05441 & 0.03209 & 0.10704 & 0.03988 & 0.02096 \\
\hline & Sukam 2 & 62 & 60 & 70 & 50 & 67 & 0.05478 & 0.01416 & 0.12040 & 0.05525 & 0.04549 \\
\hline & Jungma 4 & 59 & 60 & 60 & 50 & 67 & 0.04733 & 0.01081 & 0.06711 & 0.02957 & 0.01977 \\
\hline & Changchon1 & 25 & 10 & 57 & 10 & 23 & 0.04101 & 0.00445 & 0.04421 & 0.00957 & 0.01861 \\
\hline & Hama 1 & 13 & 20 & 3 & 13 & 17 & 0.03493 & 0.02082 & 0.03140 & 0.01661 & 0.02723 \\
\hline & Hama 2 & 57 & 20 & 77 & 53 & 77 & 0.04422 & 0.00756 & 0.11287 & 0.06083 & 0.03724 \\
\hline & Clivus $^{*}$ & 65 & 73 & 77 & 47 & 63 & 0.06426 & 0.03144 & 0.12008 & 0.08161 & 0.02189 \\
\hline & Overall mean & 47 & 43 & 58 & 39 & 49 & 0.04250 & 0.01303 & 0.07832 & 0.03716 & 0.03024 \\
\hline
\end{tabular}

A KB, CC, JY, KG: Kyeonggi-Banwol, Chungbuk-Cheongju, Jeonbuk-Yimsil, Kyongnam-Geochang, respectively.

* Additional clone as a control.

with average stability $\left(\beta_{i}=1.00\right)$ for volume indicating that it performs relatively equal on good and poor sites as discussed by FinLAY and WILKINSON (1963). However, its overall performance for volume was disappointing. Some clones performed superior to the others only in certain environments. Clone Taebaek 1 represents a clone with high stability $\left(\beta_{\mathrm{i}}=-0.05\right)$ and performs reasonably on poor sites. However, it is also a clone with low performance for volume. On the other hand, clone Palkong 2 appears to be relatively unstable $\left(\beta_{\mathrm{i}}=7.95\right)$ since it is sensitive to sites and performs very well only in favorable sites. The stability of a genotype over a range of environments has been measured by the mean square deviations from the regression (EBERHART and RUSSELL, 1966), the regression of its mean to an environmental index (FINLAY and WILKINSON, 1963), or combina- tions of these parameters. In Korea, a number of poplar clones were selected based on stability analyses. Some of these include clones that are disease resistant ( $\mathrm{NOH}$ and LEE, 1983a), those with stable overall growth performance in planting environments (NOH and LEE, 1983b), and those with stable early growth in planting environments (NoH et al., 1997).

The regression coefficient for stability analysis measures the relative performance of the clone. CLAIR and KLEINSCHMIT (1986) emphasized that the information is useful to distinguish genotypes for specific environments. However, the information is useless if all environments tested are in a single planting zone and each represents the same proportion of area to be planted. If the number of environments and genotypes is sufficiently large and the environmental range is sufficiently 
broad, the linear regression using the mean of all genotype must be valid (FRIPP and CATEN, 1971). In this study, each test site was represented by either 24 or 38 clones. The number of clones tested and the range of site quality were sufficient to justify the use of regression method. Although some clones are missing in either 1991 or 1992 planting sites, GLM procedure with overlapping individuals confirmed no difference for volume between the two planting years.

The accuracy of yield prediction of a genotype in different environments is very important in forest tree breeding. This may be measured by the mean square deviations $\left(\mathrm{s}_{\mathrm{i}}^{2}\right)$ from the regression line. Clones that have high stability have relatively low mean square deviations (BECKER, 1981). In the present study, the clones Sokwang 31 and Ssangjon 9 appeared to be very stable as shown by $\mathrm{s}^{2}{ }_{\mathrm{i}}\left(\mathrm{s}^{2}{ }_{\mathrm{i}}=0.01\right.$, respectively). These clones are predicted to perform well in a wide range of environments in Korea. However, adaptability is not the only criterion when we select superior clones. We also consider other factors such as growth performance, regression coefficient, and other stability parameters.

Table 3. - Survival rate and mean 12-year volumes of 39 P. davidiana clones planted in 1992.

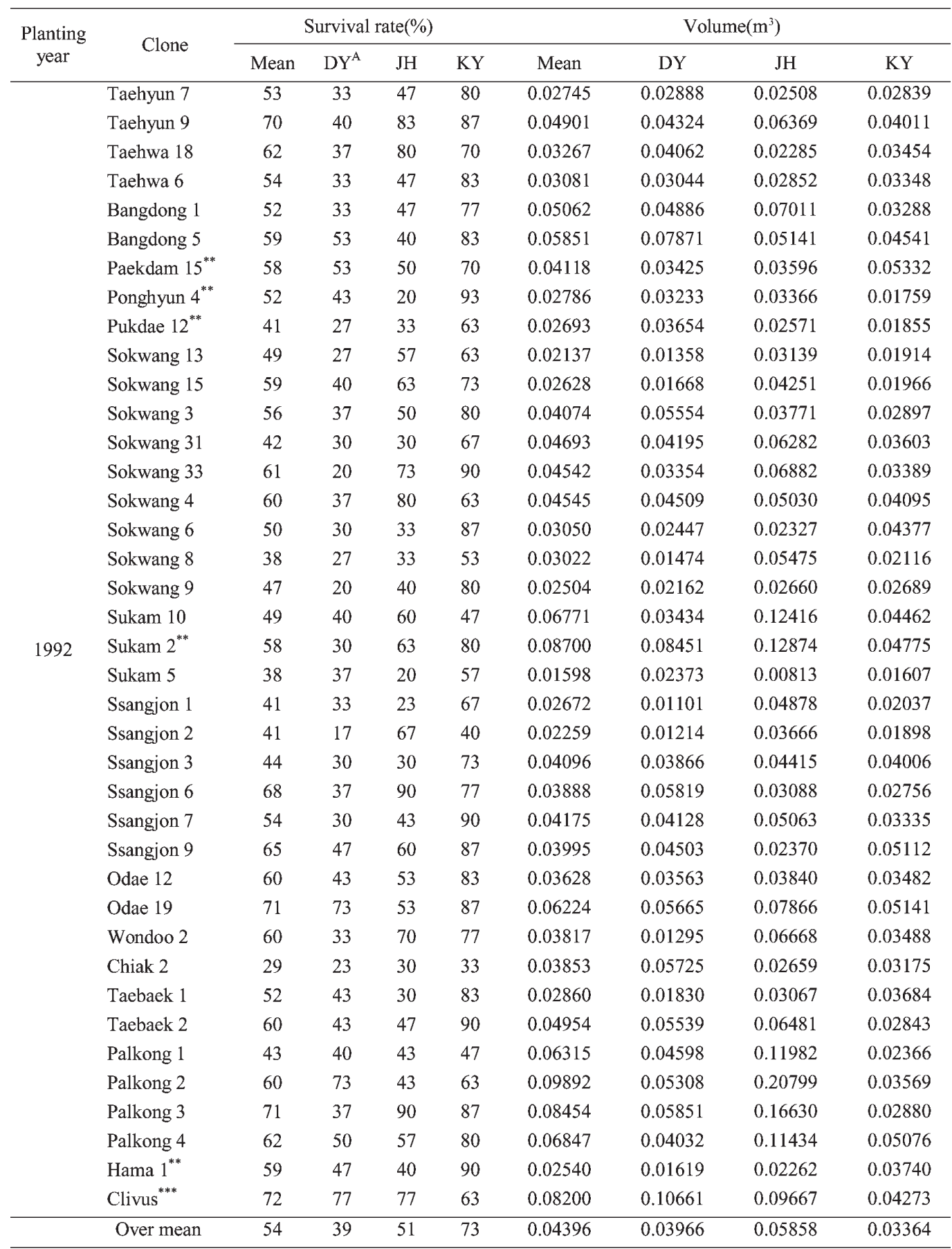

в DY, JH, KY: Daejeon-Youseong, Jeonnam-Hwasoon, Kyongbuk-Youngju, respectively.

** Overlapping clones.

*** Additional clone as a control. 
Table 4. - Comparisons of the number of clones and trees, mean volume, and the results of multiple range tests among sites.

\begin{tabular}{lccccccc}
\hline Region & CC & JH & JY & DY & KY & KG & KB \\
\hline Planting year & 1991 & 1992 & 1991 & 1992 & 1992 & 1991 & 1991 \\
No of clones & 24 & 38 & 24 & 38 & 38 & 24 & 24 \\
No of trees & 415 & 576 & 279 & 428 & 840 & 355 & 306 \\
& 0.0783 & 0.0586 & 0.0372 & 0.0397 & 0.0336 & 0.0302 & 0.0130 \\
Volume $\left(\mathrm{m}^{3}\right)^{*}$ & $\mathrm{~A}$ & $\mathrm{~B}$ & $\mathrm{C}$ & $\mathrm{C}$ & $\mathrm{C}$ & & \\
& & & & $\mathrm{D}$ & $\mathrm{D}$ & $\mathrm{D}$ & $\mathrm{E}$ \\
\hline
\end{tabular}

* Grouping by Ryan-Einot-Gabriel-Welsch multiple range test at $5 \%$ level.

Table 5. - Analyses of variance for 12-year volume of $P$. davidiana clones at each site.

\begin{tabular}{rrrrrrrrrrrrrrrrrrr}
\hline Site & \multicolumn{1}{c}{ KB } & \multicolumn{1}{c}{ CC } & \multicolumn{1}{c}{ JY } & \multicolumn{1}{c}{ KG } & \multicolumn{1}{c}{ DY } & \multicolumn{2}{c}{ JH } & \multicolumn{2}{c}{ KY } \\
\hline Source & d.f. & MS $^{\mathrm{B}}$ & d.f. & MS & d.f. & MS & d.f. & MS & d.f. & MS & d.f. & MS & d.f. & MS \\
\hline Clone $^{\mathrm{A}}$ & 23 & $86^{*}$ & 23 & $1406^{*}$ & 23 & $281^{\mathrm{N}}$ & 23 & $312^{*}$ & 37 & $355^{*}$ & 37 & $3041^{*}$ & 37 & $236^{*}$ \\
Block & 2 & $356^{*}$ & 2 & $1029^{*}$ & 1 & $783^{*}$ & 2 & $941^{*}$ & 2 & $153^{\mathrm{N}}$ & 2 & $3887^{*}$ & 2 & $969^{*}$ \\
Cl $\times$ Blk & 39 & $21^{*}$ & 44 & $277^{*}$ & 21 & $142^{*}$ & 39 & $89^{*}$ & 62 & $118^{*}$ & 65 & $1028^{*}$ & 71 & $91^{*}$ \\
Error & 241 & 10 & 345 & 96 & 233 & 37 & 290 & 26 & 326 & 48 & 471 & 133 & 729 & 28 \\
\hline
\end{tabular}

A: Cl_Blk was used as an error term.

B: MS was multiplied with their original value by 1,000 .

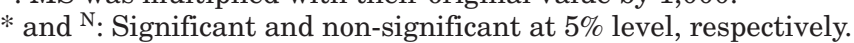

\section{Best performance or stability}

The effect of genotype-environment interaction can be reduced by creating groups of essentially homogeneous environments and selecting cultivars suitable for each environment, and by developing stable cultivars which perform dependably over wide range of environments (ClAir and KleinsCHMit, 1986). The significant clone $\mathrm{x}$ site interaction shown in the present study implies that clones perform differently in different sites (Figure 1). Earlier, IsIK et al. (1995) reported different survival rates in Norway spruce among regions at age 17 and noticed a serious interaction effect between clones and regions. CLAIR and KLEINSCHMIT (1986) also postulated that clone $\mathrm{x}$ site interaction for 10-year height growth in Norway spruce might have reduced by selection of stable clones.

If there is a site $\mathrm{x}$ clone interaction in the analysis of variance over sites, a more rational approach to selection of superior clones is necessary. For example, a combination of genotypic stability and growth performance should be considered in order to obtain clones, which are stable over a wide range of environments as well as superior in performance. In this study, selection of clones after setting an acceptable value for a stability parameter followed by selection based on growth performance may be more practical (CLAIR and KLEINSCHMIT, 1986). CURNEI et al. (2003) suggested that selection would reduce the interaction between clones and regions for height, $\mathrm{DBH}$, and susceptibility to an anthracnose of wild cherry. HoLLAND et al. (2002) selected highly adapted oat to various environments and increased productiv- ity. In this study, five clones (Odae 19, Taehyun 9, Sunyeo 4, Sokwang 31, Taehyun 3) were selected as superior generalists based on mean volume greater than $0.0408 \mathrm{~m}^{3}$, absolute value of regression coefficient by less than $1.5(1 \pm 0.5)$, and mean square deviations by less than 0.5 (Figure 1). The average volume of the five superior clones was $0.049 \mathrm{~m}^{3}$ and selection effect was $19.3 \%$ compared with the average of 57 clones.

Based on multiple range test $(\alpha=0.05)$ for volume among clones regardless of their planting sites, the clones could be divided into 18 groups (data not shown). The clones Palkong 2 and 3, and Sukam 2 formed the best group (Table 6). Among the 18 groups, 20 clones (from $7^{\text {th }}$ to $26^{\text {th }}$ in rank) were the same group in which all five selected superior clones were included in the group. Therefore, there was no real difference in volume among the selected clones. The influence of volume against stability parameters was analyzed with all clones except the clone Taehyun 1, which had too high $\mathrm{s}_{\mathrm{i}}^{2}(14.70)$.

Linear regression between volume and the parameters was as follows:

$$
\begin{aligned}
& |1-\beta|=0.0044 \times \text { volume }+0.8525\left(R^{2}=0.374\right) \\
& \mathrm{s}^{2}{ }_{\mathrm{i}}=0.0044 \times \text { volume }+0.2818\left(\mathrm{R}^{2}=0.159\right)
\end{aligned}
$$

A positive relationship between stability parameters and the clone mean performance for volume was noted in this study. Thus, the higher mean volume a clone has, the worse the stability parameters become (i.e. increasing $\beta_{\mathrm{i}}$ ). In other words, fast growing clones tend to be more sensitive to environmental changes. This kind of 


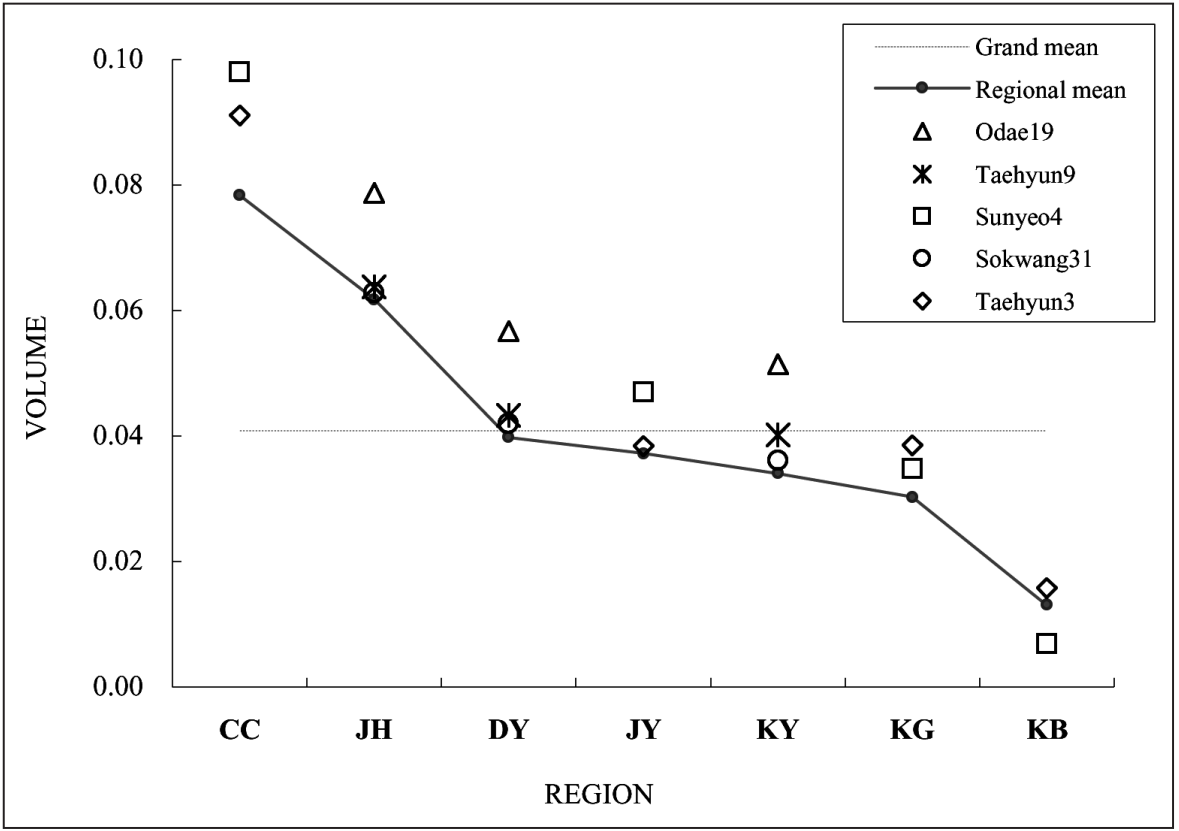

Figure 1. - Volume of five selected Populus davidiana clones based on their mean volume and stability parameters at each region.

relationship has also been found in a pine (LIAND and MCKEAND, 1989) and crop plants (FINLAY and WILKINSON, 1963; GRAY, 1982), implying that the superior hereditary characteristics would be expressed most in the optimal environments. LIAND and McKEAND (1989) reported that half-sib families of loblolly pine selected by stability analysis for both volume and resistance to fusiform rust could contribute to high productivity. A number of aspen hybrids have been known. However, the morphology, growth performance, and wood characteristics varied among the hybrids (THOMAs et al., 1997).
Knowing the high clone-region interactions in height growth in hybrid poplar, Yu (2001) stressed the importance of both clone selection for their adaptation to each local region and use of a limited number of selected clones. YU and PULKKINEN (2003) also reported that hybrid aspen clones varied in growth performance among regions (between farm land and forest land), and that the ranking of growth (height and $\mathrm{DBH}$ ) was not stable.

NoH et al. (1997) selected 11 clones based on both stability parameters and six-year height growth with the

Table 6. - Mean 12-year volumes for 57 clones and stability statistics for the volumes of $P$. davidiana.

\begin{tabular}{|c|c|c|c|c|c|c|c|c|c|c|c|c|c|}
\hline Clone & $\begin{array}{l}\text { Volume } \\
\left(100 \mathrm{~cm}^{3}\right)\end{array}$ & Rank & $\beta_{\mathrm{i}}$ & Rank & $\mathrm{s}^{2}{ }_{\mathrm{i}}$ & Rank & Clone & $\begin{array}{l}\text { Volume } e^{A} \\
\left(100 \mathrm{~cm}^{3}\right)\end{array}$ & Rank & $\beta_{\mathrm{i}}$ & Rank & $\mathrm{s}_{\mathrm{i}}^{2}$ & Rank \\
\hline Palkong 2 & 989 & 1 & 7.95 & 1 & 4.68 & 51 & Chiak 2 & 385 & 30 & -0.58 & 42 & 4.47 & 49 \\
\hline Palkong 3 & 845 & 2 & 6.13 & 2 & 0.23 & 16 & Wondoo 2 & 382 & 31 & 1.79 & 7 & 5.65 & 53 \\
\hline Sukam 2 & 708 & 3 & 1.90 & 6 & 2.48 & 44 & Odae 12 & 363 & 32 & 0.16 & 52 & 0.00 & 1 \\
\hline Palkong 4 & 685 & 4 & 3.15 & 5 & 4.51 & 50 & Sunyeo 6 & 358 & 33 & 0.98 & 27 & 0.68 & 30 \\
\hline Sukam 10 & 677 & 5 & 3.91 & 4 & 5.95 & 54 & Ponghyun 4 & 346 & 34 & 0.79 & 32 & 1.79 & 41 \\
\hline Palkong 1 & 632 & 6 & 4.27 & 3 & 0.05 & 9 & Kooma 1 & 345 & 35 & 1.24 & 18 & 0.26 & 18 \\
\hline Odae 19 & 622 & 7 & 1.22 & 19 & 0.02 & 5 & Jungma 4 & 331 & 36 & 0.85 & 31 & 0.22 & 15 \\
\hline Sunyeo 3 & 601 & 8 & 1.67 & 9 & 6.35 & 56 & Taehwa 18 & 327 & 37 & -0.63 & 40 & 0.52 & 26 \\
\hline Bangdong 5 & 585 & 9 & -0.15 & 54 & 6.24 & 55 & Kooma 2 & 323 & 38 & 1.00 & 26 & 2.59 & 45 \\
\hline Hama2 & 550 & 10 & 1.59 & 11 & 0.67 & 29 & Taehwa 6 & 308 & 39 & -0.20 & 51 & 0.02 & 5 \\
\hline Paekdam 5 & 546 & 11 & 1.44 & 15 & 2.21 & 43 & Sokwang 6 & 305 & 40 & -0.72 & 34 & 1.21 & 37 \\
\hline Bongdong 1 & 506 & 12 & 1.56 & 12 & 0.24 & 17 & Sokwang 8 & 302 & 41 & 1.68 & 8 & 1.43 & 38 \\
\hline Paekdam 15 & 496 & 13 & 1.11 & 24 & 4.44 & 48 & Taebaek 1 & 286 & 42 & -0.05 & 57 & 1.78 & 40 \\
\hline Taebak 2 & 495 & 14 & 1.37 & 16 & 1.89 & 42 & Pukdae 12 & 277 & 43 & 0.71 & 37 & 0.82 & 33 \\
\hline Taehyun 9 & 490 & 15 & 1.08 & 25 & 0.06 & 10 & Taehyun 7 & 275 & 44 & -0.16 & 52 & 0.01 & 2 \\
\hline Sunyeo 4 & 474 & 16 & 1.35 & 17 & 0.10 & 12 & Pukdae 11 & 270 & 45 & 0.77 & 33 & 0.16 & 13 \\
\hline Sokwang 31 & 469 & 17 & 1.19 & 22 & 0.01 & 2 & Ssangjon 1 & 267 & 46 & 1.47 & 14 & 1.74 & 39 \\
\hline Sukam 1 & 466 & 18 & 1.48 & 13 & 1.12 & 36 & Sokwang 15 & 263 & 47 & 1.12 & 23 & 0.49 & 24 \\
\hline Sokwang 4 & 455 & 19 & 0.39 & 47 & 0.02 & 5 & Ponghyun 1 & 262 & 48 & 0.72 & 34 & 0.35 & 21 \\
\hline Sokwang 33 & 454 & 20 & 1.66 & 10 & 0.55 & 27 & Sokwang 9 & 250 & 49 & 0.06 & 56 & 0.17 & 14 \\
\hline Pukdae 7 & 449 & 21 & 0.91 & 29 & 3.18 & 46 & Ssangjon 2 & 226 & 50 & 0.93 & 28 & 0.81 & 32 \\
\hline Taehyun 3 & 447 & 22 & 1.22 & 19 & 0.30 & 20 & Hama 1 & 222 & 51 & 0.28 & 48 & 1.07 & 35 \\
\hline Pukdae 6 & 442 & 23 & 0.89 & 30 & 0.76 & 31 & Pukdae 9 & 218 & 52 & 0.46 & 45 & 0.86 & 34 \\
\hline Ssangjon 7 & 418 & 24 & 0.72 & 34 & 0.07 & 11 & Sokwang 13 & 214 & 53 & 0.65 & 38 & 0.47 & 23 \\
\hline Ssangjon 3 & 410 & 25 & 0.21 & 50 & 0.04 & 8 & Changchon 1 & 190 & 54 & 0.62 & 41 & 0.50 & 25 \\
\hline Sokwang 3 & 407 & 26 & 0.07 & 55 & 3.66 & 47 & Pukdae 3 & 167 & 55 & 0.46 & 45 & 0.42 & 22 \\
\hline Ssangjon 9 & 400 & 27 & -1.22 & 19 & 0.01 & 2 & Sukam 5 & 160 & 56 & -0.48 & 43 & 0.59 & 28 \\
\hline Taehyun 1 & 390 & 28 & 0.65 & 38 & 14.70 & 57 & Sangma 1 & 145 & 57 & 0.48 & 43 & 0.27 & 19 \\
\hline Ssangjon 6 & 389 & 29 & -0.24 & 49 & 5.48 & 52 & Overall mean ${ }^{\mathrm{B}}$ & 408 & & 1.09 & & 1.74 & \\
\hline
\end{tabular}

${ }^{A}$ and ${ }^{B}$ : Volume and overall mean were computed from the mean values of each block in sites and those of each clone, respectively. 
same materials that we used in this study. They selected seven clones out of 11 that perform relatively well in all tested sites, one clone that performs well in good sites, and 3 clones that perform relatively well in poor sites. Among the five selected clones, the three (Taehyun 3 and 9, and Odae 19) were overlapped by the present study, indicating that stability has an age-age correlation. Most clones appeared to maintain their relative rank orders at the same level till age 12 .

The purpose of early selection in tree breeding is to shorten the generation interval (WU, 1998), and if early selection is to be successful, there must be a high genetic correlation between a younger age and rotation age (ZoBel and TALBERT, 1984). When $\mathrm{NoH}$ et al. (1997) selected the stable clones at age 6 , the correlation coefficient between ages six and 32 (the age at harvest) was 0.87 . Therefore, if we select a stable clone based on the correlation coefficient ( $\left.\mathrm{R}^{2}: 0.76\right)$, we are accepting the risk of $24 \%$ erroneous selection.

Clonal forestry is being utilized as an important tool in many tree breeding programs. While most breeders agree on the necessity of breeding of many varieties to maintain diversity, there arise some economic as well as management problems when we use the diversity. How many clones do we use for clonal forestry? Other problems have also been addressed (HüHN, 1992). If we consider only economic effect, genetic gain was highest in the clone Odae 19 since it ranked in top seven $\left(0.0622 \mathrm{~m}^{3}\right)$ for volume, 1.22 for regression coefficient (closer to one), and 0.02 for variance of deviation (closer to zero). However, it may be reasonable to select about four to five clones to cope with unexpected environmental disasters at the expense of reducing a little gain. Forest tree breeders would have opportunities to select clones for different stabilities under various environmental conditions if there is clonal variation in stability and growth performance among clones.

Therefore, the following major findings could be summarized from this study: (1) the selected $P$. davidiana clones have the average stability of $\beta$ i from 1.08 to 1.35 (criteria: $1 \pm 0.5$ ), indicating high stability of predicting clonal performance in a wide range of environments. (2) the volume production of the five selected clones at age 12 was greater than $0.0447 \mathrm{~m}^{3}$ (overall mean 0.0408 ) resulting in genetic gain by $19.3 \%$ above the overall mean, and (3) the mean square deviations were less than 0.3 (criteria: 0.5 ), indicating the high stability of the selected clones across different environments.

These results suggest that the selected clones could be planted across Korea. Of course, additional studies are needed to select and breed aspen clones with more specific site conditions and predictable performance in more various conditions.

\section{References}

Barnes, R. D., J. Burley, G. L. Gibson and J. P. Garcia DE LEON (1984): Genotype-environment interactions in tropical pines and their effects on the structure of breeding populations. Silvae Genetica. 33: 186-198.

BECKER, H. C. (1981): Measures of phenotypic stability. Euphytica 10: 835-840.
BentZer, B. G. (1981): Large scale propagation of Norway spruce (Picea abies (L.) KARst.) by cuttings. In: Symp. on Clonal Forestry. Swed. Univ. Agr. Research Notes 32, pp. 32-42.

Bentzer, B. G., G. S. Foster, A. R. Hellberg and A. G. PoDzORSKI (1988): Genotype x environment interaction in Norway spruce involving three levels of genetic control: seed source, clone mixture, and clone. Can. J. For. Res. 18: 1172-1181.

ClaiR, J. B. S. and J. KLeinschmit (1986): Genotype-environment interaction and stability in ten-year height growth of Norway spruce clones (Picea abies KARST.). Silvae Genetica 35: 177-186.

CURNeI, Y., D. JACQUES and A. NANSON (2003): First multisite clonal test of wild cherry (Prunus avium L.) in Belgium. Silvae Genetica 52: 45-52.

EBERHART, S. A. and W. A. RUsSELL (1966): Stability parameters for comparing varieties. Crop Science 6: 36-40.

FINLAY, K. W. and G. N. WILKINSON (1963): The analysis of adaptation in a plant-breeding programme. Aust. J. Agric. Res. 14: 742-754.

FRIPP, Y. J. and C. E. CATEN (1971): Genotype-environmental interactions in Schizophyllum commune. I. Analysis and character. Heredity 27: 393-407.

GRAY, E. (1982): Genotype x Environment interactions and stability analysis for forage yield of orchard grass clones. Crop Sci. 22: 19-23.

Holland, J. B., A. BJornstad, K. J. Frey, M. Gullord and D. M. WEsEnBERG (2002): Recurrent selection for broad adaptation affects stability of oat. Euphytica 126: 265-274.

HüHN, M. (1992): Multiclonal mixtures and number of clones. Number of clones and yield stability (deterministic approach with competition). Silvae Genetica 41: 205-213.

HYNYEN, J. and K. KARLSSON (2001): Intensive management of hybrid aspen in Finland. Management and utilization of broadleaved tree species in Nordic and Baltic countries - Birch, aspen, alder. Workshop, $16^{\text {th }}-18^{\text {th }}$ of May, Finland.

HYUN, S. K. and S. C. Hong (1959): Inter- and intraspecies hybrids in poplars. 1. List of poplar hybrids produced by the Inst. of Forest Genetics in Suwon. Res. Rep. Inst. For. Gen. No. 1: 61-71.

IsIK, K., J. Kleinschmit and J. Svolba (1995): Survival, growth trends and genetic gains in 17-year old Picea abies clones at seven test sites. Silvae Genetica 44: $116-128$.

IsIK, K. and J. KLEINSCHMIT (2003): Stability-related parameters and their evaluation in a 17-year old Norway spruce clonal test series. Silvae Genetica 52: 133-139.

JoNG, S. K. and J. L. BREWBAKER (2005): Genotype x environment interaction of maize hybrids among temperate and tropical inbreeds in temporal and spatial environments. Korean J. Breed. 37: 17-26.

KLEINSChMiT, J. and J. SCHMidT (1977): Experiences with Picea abies cuttings propagation in Germany and problems connected with large-scale application. Silvae Genetica 26: 197-203.

Korea Forest Service (1992): Statistical Yearbook of Forestry. No 33, 411pp.

Liand, B. and S. E. McKeand (1989): Stability of loblolly pine families in the southeastern U.S. Silvae Genetica 38: 96-101.

NoH, E. R., Y. B. Koo and S. K. LEE (1997): Selection of Populus davidiana Dode clone using stability analysis. Res. Rep. For. Gen. Res. Inst. 33: 1-13. 
NoH, E. R., Y. B. Koo and C. S. SHIM (1992): Breeding of aspen (Populus davidiana Dode) in Korea. Proceeding of $19^{\text {th }}$ Session of the Internal Poplar Commission, Vol. 1: 403-412.

NoH, E. R. and S. B. LEE (1983a): Selection of superior clones in newly introduced resistant poplars to diseases. Res. Rep. Inst. For. Gen. 19: 28-35.

NoH, E. R. and S. K. LEE (1983b): Reselection of Populus alba $\times$ P. glandulosa F1 clones using stability analysis. Res. Rep. Inst. For. Gen. 19: 20-27.

NoH, E. R., S. K. LEE and Y. B. Koo (1990): Determination of early selection age using age-to-age correlation in Populus davidiana Dode. Res. Rep. Inst. For. Gen. 26: 10-21.

Noh, E. R., S. K. Lee, Y. B. Koo and K. H. Chung (1988): A mass propagation method of aspen (Populus davidiana Dode) using tissue culture and juvenile cutting techniques. Res. Rep. Inst. For. Gen. 24: 20-27.

Paul, A. D., G. S. Foster, T. CAldwell and J. McRae (1997): Trends in genetic and environmental parameters for height, diameter, and volume in a multilocation clonal study with loblolly pine. For. Sci. 43: 87-98.

PERKINS, J. M. and J. L. JinKs (1968): Environmental and genotype environmental components of variability. III. Multiple lines aNd crosses. Heredity 23: 339-356.
SAS InstiTUTE INC. (1989): SAS/STAT User's guide, Version $6,4^{\text {th }}$ edition, volume 2 . SAS Institute Inc. USA. $846 \mathrm{pp}$.

Thomas, B. R., S. E. MacDonald and B. P. DANCIK (1997): Variance components, heritabilities and gain estimate for growth chamber and field performance of Populus tremuloides: growth parameter. Silvae Genetica. 46: 317-326.

WU, H. X. (1998): Study of early selection in tree breeding. I. Advantage of early selection through increase of selection intensity and reduction of field test size. Silvae Genetica. 47: 146-155.

YeIseR, J. L., J. P. vAN BuIJTENEN and W. J. LOWE (1981): Genotype $\mathrm{x}$ environment interactions and seed movement for loblolly pine in the Western Gulf Region. Silvae Genetica. 36: 196-200.

YU, Q. (2001): Selection and propagation of hybrid aspen clones for growth and fibre quality. Dept. of Applied Biology, University of Helsinki, Publication no. 6.

YU, Q. and P. PulKkinen (2003): Genotype-environment interaction and stability in growth of aspen hybrid clones. Forest Ecology and Management 173: 25-35.

ZoBel, B. and J. TALBERT (1984): Applied tree improvements. John Wiley \& Sons, New York. 505 pp.

\title{
Genotype-Species Interactions in Neighbourhoods of Forest Tree Communities
}

\author{
By Chr. Wehenkel, F. Bergmann and H.-R. Gregorius
}

Institut für Forstgenetik und Forstpflanzenzüchtung, Büsgenweg 2, 37077 Göttingen, Germany

(Received 13 ${ }^{\text {th }}$ December 2005)

\begin{abstract}
Studies on plant communities of various annual species suggest that there are particular biotic interactions among individuals from different species which could be the basis for long-term species coexistence. In the course of a large survey on species-genetic diversity relationships in several forest tree communities, it was found that statistically significant differences exist among isozyme genotype frequencies of conspecific tree groups, which differ only by species identity of their neighbours. Based on a specific measure, the association of the neighbouring species with the genotypes of the target species or that of the genotypes with the neighbouring species was quantified. Since only AAT and HEK of the five analysed enzyme systems differed in their genotype frequencies among several tree groups of the same target species, a potential involvement of their enzymatic function in the observed differences was discussed. The results of this study demonstrate a finescale genetic differentiation within single tree species of forest communities, which may be the result of biotic interactions between the genetic structure of a species
\end{abstract}

and the species composition of its community. This observation also suggests the importance of intraspecific genetic variation for interspecific adaptation.

Key words: Association, tree species, neighbourhood, isozymes, species-genotype interaction.

\section{Introduction}

It has generally been recognized that the adaptive genetic variation of plant species results not only from abiotic selective forces, such as stressful climatic or edaphic conditions, but also from local biotic stressors, such as herbivores, parasites and other pests of plants (for review, see MitTon, 1997). Furthermore, competition during the first ontogenetic stages by conspecific individuals or individuals from other species of related taxa may also be a selective factor shaping the genetic structure of the growing plant population (for reviews, see Silvertown, 1987, chapter 8; KedDy, 1989). However, in recent years there have been an increasing 